\title{
Treatment of Isolated Gastric Crohn's Disease with Inhaled Corticosteroids
}

\author{
Samar H. Ibrahim ${ }^{a}$ Thomas C. Smyrk ${ }^{b}$ William A. Faubion ${ }^{c}$ \\ aPediatric and Adolescent Medicine Department, b Laboratory Medicine and \\ Pathology Department and 'Gastroenterology Department, Mayo Clinic, \\ Rochester, Minn., USA
}

\section{Key Words}

Gastric Crohn's disease · Gastric outlet obstruction · Inhaled corticosteroids

\begin{abstract}
Isolated gastric Crohn's disease is unusual and a rare cause of pyloric outlet obstruction. If medical therapy is ineffective, patients may require surgery to relieve gastric outlet obstruction. Herein we describe a patient with isolated gastric Crohn's disease with pyloric outlet obstruction who was steroid-dependent and had a relapse despite receiving biologic and immunomodulatory therapy, but ultimately responded to topical treatment with inhaled corticosteroids.
\end{abstract}

\section{Introduction}

Crohn's disease of the stomach is uncommon and usually occurs concomitantly with disease elsewhere in the gastrointestinal tract. Limited published data report a variable response to systemic medical therapy frequently leading to surgical intervention. In this report, we describe a patient with steroid-dependent Crohn's disease involving the gastric antrum who responded to swallowed topical steroid therapy, allowing tapering and discontinuation of systemic corticosteroids after seven years of continuous corticosteroid therapy.

\section{Case Report}

A 26-year-old woman presented to the Mayo Clinic for further evaluation of a seven-year history of inflammatory pyloric outlet stricture compatible with gastric Crohn's disease. She had suffered from symptoms of gastric outlet obstruction (abdominal pain, early satiety, bloating, and burping after meals) intermittently over the last seven years, and multiple biopsies had demonstrated a chronic inflammatory infiltrate with granuloma compatible with Crohn's disease. 
Prior to her visit to our institution, she had been treated with prednisone, proton pump inhibitors, and thiopurines, yet no medical therapy had resulted in a significant steroid-sparing effect. Ultimately, she was treated with infliximab and achieved a two-year remission, at which point infliximab was discontinued. Upon recurrence of vomiting, resumption of infliximab therapy resulted in mild arthralgias and ultimately in an acute infusion-related reaction. She was then managed with systemic steroids and was on prednisone $10 \mathrm{mg}$ orally per day and on azathioprine $75 \mathrm{mg}$ orally twice per day upon presentation. She had frequent balloon dilatation until her referral to our institution.

Review of her history demonstrated no extraintestinal manifestations of disease and no family history of inflammatory bowel disease. She is a lifetime nonsmoker. Abdominal exam revealed obvious gastric distention but limited tympany. She had mild epigastric tenderness, but normal bowel sounds in each quadrant. CT enterography demonstrated distention of the stomach with a short inflammatory stricture involving the pylorus (fig. 1). Upper endoscopy showed a pinpoint pyloric opening not amenable to passage of a balloon for dilation, with chronic changes of the antrum compatible with gastric Crohn's disease. Helicobacter pylori testing was negative. The gastric biopsies showed fundic-type mucosa with moderate active chronic gastritis (fig. 2). Serum serology demonstrated positive titers for anti-Saccharomyces cerevisiae antibodies but no anti-neutrophil cytoplasmic antibodies, compatible with the diagnosis of Crohn's disease.

Due to her past response to anti-tumor necrosis factor alpha (anti-TNFa) therapy, adalimumab therapy was begun with an initial dose of $80 \mathrm{mg}$ followed by $40 \mathrm{mg}$ every two weeks. Prednisone and azathioprine were continued. There was no significant clinical improvement over the ensuing three months. Thus at the subsequent visit, we introduced topical corticosteroid therapy with swallowed fluticasone two puffs twice daily. One month later she was able to taper off prednisone and maintain her clinical remission. Follow-up esophagogastroduodenoscopy six and twelve months after beginning swallowed fluticasone therapy demonstrated significant improvement in the pyloric stricture with easy passage of the endoscope through the pylorus. Biopsies demonstrated only mild inflammation (fig. 3 ). Adalimumab was discontinued six months after the last esophagogastroduodenoscopy; the patient remained on topical fluticasone and azathioprine. Over the two years the patient has remained asymptomatic without need for systemic corticosteroids.

\section{Discussion}

Crohn's disease is a common chronic inflammatory condition that may involve any part of the gastrointestinal tract from the mouth to the anus. Crohn's disease presenting in young patients most commonly affects the terminal ileum and cecum (roughly two thirds of patients) and less commonly is isolated to the colon (10\%) or upper gastrointestinal tract (20\%) [1]. Isolated gastroduodenal disease is quite uncommon, described in fewer than $4 \%$ of patients [2].

Patients with gastric Crohn's disease commonly present with symptoms of gastric outlet obstruction such as upper abdominal pain and vomiting. Other causes of pyloric inflammatory strictures must be excluded and include peptic ulcer disease, nonsteroidal antiinflammatory drug abuse, malignancy, and other rare immune-mediated diseases such as sarcoidosis. The clinical history, endoscopic findings, and biopsy findings of chronic granulomatous inflammation led to the diagnosis of Crohn's disease in this patient.

Historically one third of patients with gastroduodenal Crohn's disease have required a variety of surgical approaches [2]. Surgical resection of the inflammatory stricture is associated with increased morbidity $[3,4]$; thus the operation of choice has been gastrojejunostomy relieving the pyloric obstruction [4]. As with all operative interventions for Crohn's disease, surgery is an adjunct to medical therapy as marginal ulceration and Crohn's recurrence frequently complicates this operation [4]. Stricturoplasty has been described in selected patients with duodenal Crohn's disease, but recurrence and perforating disease at the site of stricturoplasty are common complications [5]. 
Case reports and case series describe variable response rates to established immunosuppressive anti-Crohn's therapy. Corticosteroids and parenteral nutrition have been reported to be effective in acute gastric outlet obstruction secondary to Crohn's disease [6]. Thiopurines appear to be effective for maintenance therapy in duodenal disease [7] and therefore would appear to be reasonable alternatives in gastric Crohn's disease. Methotrexate has a proven role in the maintenance of remission in Crohn's disease [8], yet there are no reports specific to isolated gastric Crohn's disease. Single case reports have described the efficacy of anti-TNF therapy [9] and calcineurin inhibitors $[7,10]$ for severe upper intestinal Crohn's disease. Our patient experienced an initial response to infliximab, but was ultimately unable to taper systemic corticosteroids despite adequate anti-TNF therapy. Endoscopic balloon dilatation has been described as adjunctive therapy to aggressive medical intervention [11] but high recurrence rates tend to lead to surgery [12].

After the application of potent topically active corticosteroid inhalers was proven to provide safe and effective therapy of eosinophilic esophagitis [13], we applied the same principle to the treatment of gastric Crohn's disease with good results. Adverse effects caused by inhaled corticosteroids include thrush and dysphonia [14]. Other well-documented adverse effects of corticosteroids include adrenal suppression and growth retardation in children, but clearly the potential for systemic effects of inhaled corticosteroid is greatly diminished in comparison with the effects of systemic administration. The use of the inhaler without a spacer allows more corticosteroid to be deposited in the esophagus and the stomach so that they may be absorbed to a greater degree through the gastrointestinal tract. However, it has been suggested that adverse systemic effects of inhaled steroids are dependent on pulmonary rather than gastrointestinal absorption because steroid absorbed from the gastrointestinal tract undergoes first-pass metabolism in the liver [15].

While our patient received adalimumab for 3 months before presentation to our institution and for 6 months together with the inhaled corticosteroid afterward, she is off adalimumab for 18 months now without relapse. It is thus less likely that this patient who was steroid-dependent before initiating the fluticasone application improved because of adalimumab rather than because of fluticasone.

In conclusion, although isolated gastric Crohn's disease is a relatively rare condition, the symptoms of gastric outlet obstruction tend to be refractory to conventional therapy. We report inhaled corticosteroid as a novel approach for the management of a patient with gastric Crohn's disease. Inhaled corticosteroids appear to be a safe and effective alternative to oral steroid therapy in patients with gastric Crohn's disease, as noted after 2 years of treatment in our patient. This approach may provide effective relief while attenuating the long-term side effects of conventional steroid therapy. 


\begin{tabular}{r|l|l|l} 
Case Reports in & $\begin{array}{l}\text { Case Rep Gastroenterol 2008;2:363-368 } \\
\text { D0I: 10.1159/000158543 }\end{array}$ & Published online: November 5, 2008 & $\begin{array}{l}\text { O 2008 S. Karger AG, Basel } \\
\text { ISSN 1662-0631 } \\
\text { www.karger.com/crg }\end{array}$ \\
\hline
\end{tabular}

Fig. 1. CT enterography showing dilated stomach.

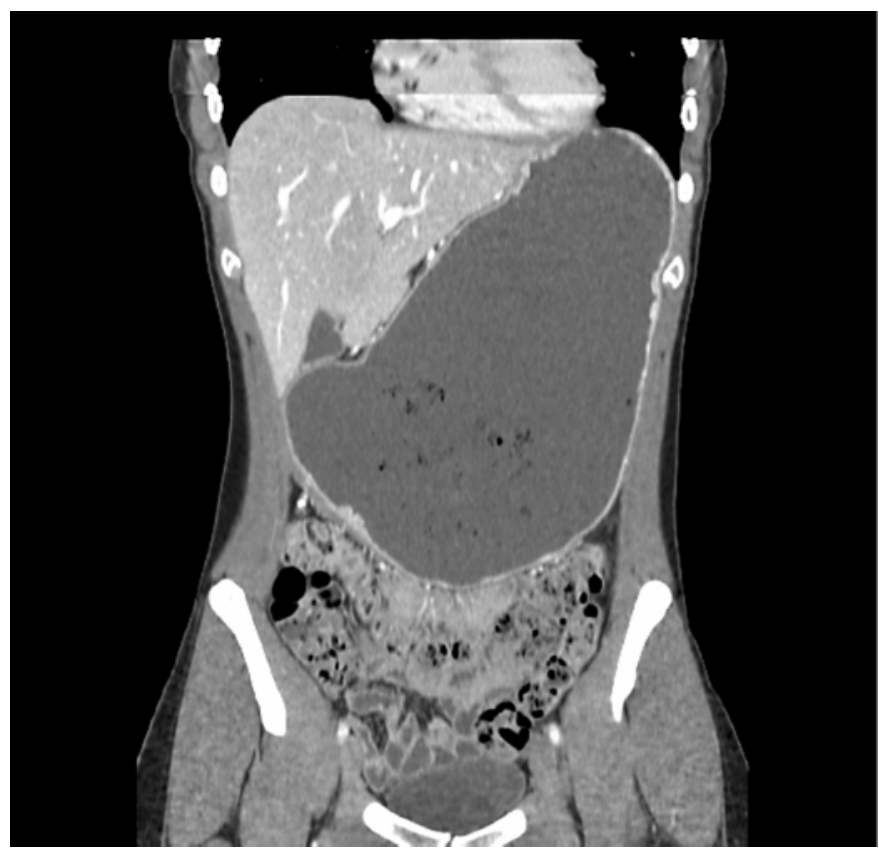

Fig. 2. Histological section of a gastric biopsy showing moderate active gastritis before beginning swallowed fluticasone therapy.

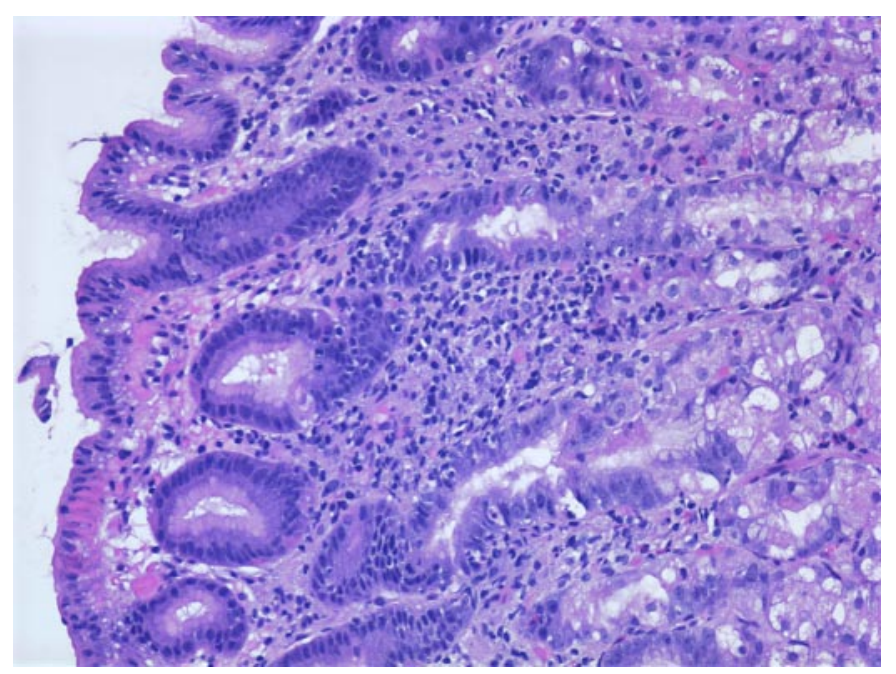




\begin{tabular}{r|l|l|l} 
Case Reports $/ \mathrm{h}$ & $\begin{array}{l}\text { Case Rep Gastroenterol 2008;2:363-368 } \\
\text { D0I: 10.1159/000158543 }\end{array}$ & Published online: November 5, 2008 & $\begin{array}{l}\text { O 2008 S. Karger AG, Basel } \\
\text { ISSN 1662-0631 } \\
\text { www.karger.com/crg }\end{array}$ \\
\hline
\end{tabular}

Fig. 3. Histological section of a gastric biopsy showing only mild inflammation six months after beginning swallowed fluticasone therapy.

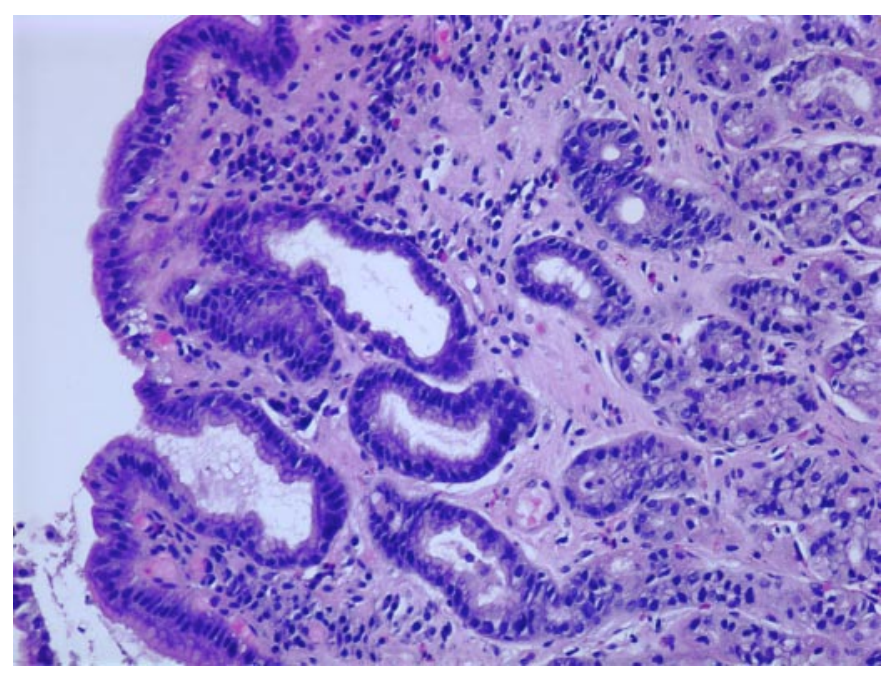




\section{References}

1 Auvin S, Molinie F, Gower-Rousseau C, et al: Incidence, clinical presentation and location at diagnosis of pediatric inflammatory bowel disease: a prospective population-based study in northern France (1988-1999). J Pediatr Gastroenterol Nutr 2005;41:49-55.

2 Fielding JF, Toye DK, Beton DC, Cooke WT: Crohn's disease of the stomach and duodenum. Gut 1970;11:1001-1006.

-3 Ross TM, Fazio VW, Farmer RG: Long-term results of surgical treatment for Crohn's disease of the duodenum. Ann Surg 1983;197:399-406.

4 Murray JJ, Schoetz DJ Jr, Nugent FW, Coller JA, Veidenheimer MC: Surgical management of Crohn's disease involving the duodenum. Am J Surg 1984;147:58-65.

5 Futami K, Arima S: Role of strictureplasty in surgical treatment of Crohn's disease. J Gastroenterol 2005;40(suppl 16):35-39.

-6 Priebe WM, Simon JB: Crohn's disease of the stomach with outlet obstruction: a case report and review of therapy. J Clin Gastroenterol 1983;5:441-445.

7 Tremaine WJ: Gastroduodenal Crohn's disease: medical management. Inflamm Bowel Dis 2003;9:127-128; discussion 131.

8 Feagan BG, Fedorak RN, Irvine EJ, et al: A comparison of methotrexate with placebo for the maintenance of remission in Crohn's disease. North American Crohn's Study Group Investigators. N Engl J Med 2000;342:1627-1632.

-9 Knapp AB, Mirsky FJ, Dillon EH, Korelitz BI: Successful infliximab therapy for a duodenal stricture caused by Crohn's disease. Inflamm Bowel Dis 2005;11:11231125 .

10 Sandborn WJ: Preliminary report on the use of oral tacrolimus (FK506) in the treatment of complicated proximal small bowel and fistulizing Crohn's disease. Am J Gastroenterol 1997;92:876-879.

-11 Murthy UK: Repeated hydrostatic balloon dilation in obstructive gastroduodenal Crohn's disease. Gastrointest Endosc 1991;37:484-485.

12 Matsui T, Hatakeyama S, Ikeda K, Yao T, Takenaka K, Sakurai T: Long-term outcome of endoscopic balloon dilation in obstructive gastroduodenal Crohn's disease. Endoscopy 1997;29:640-645.

13 Faubion WA Jr, Perrault J, Burgart LJ, Zein NN, Clawson M, Freese DK: Treatment of eosinophilic esophagitis with inhaled corticosteroids. J Pediatr Gastroenterol Nutr 1998;27:90-93.

14 Kamada AK, Szefler SJ, Martin RJ, et al: Issues in the use of inhaled glucocorticoids. The Asthma Clinical Research Network. Am J Respir Crit Care Med 1996;153:1739-1748.

15 Grove A, Allam C, McFarlane LC, McPhate G, Jackson CM, Lipworth BJ: A comparison of the systemic bioactivity of inhaled budesonide and fluticasone propionate in normal subjects. Br J Clin Pharmacol 1994;38:527-532. 